\title{
Indústria farmacêutica e psiquiatria no quadro da Sociologia Econômica. Uma agenda de pesquisa
}

Marcia Mazon

\section{Resumo}

Neste artigo, interessou-nos analisar a relação entre indústria farmacêutica e psiquiatria assim como novos contornos desta relação a partir da década de 1990 no Brasil. Argumentamos, a partir do enfoque da Sociologia Econômica, a qual entende os mercados como construções sociais, que este processo ganha um desenho particular no país. O intuito do artigo é abrir uma agenda de pesquisa na área da saúde e indústria farmacêutica a partir deste referencial. A metodologia mobilizada foi revisão bibliográfica e análise documental. Quando falamos da psiquiatria brasileira, na década de 1940 este setor lutava pelo reconhecimento profissional com o discurso da prevenção da doença,enquanto o hospital psiquiátrico buscava seu espaço. No cerne das transformações recentes da reforma da psiquiatriae dos processos de medicalização - em particular a partir da publicação do Manual Diagnóstico e Estatístico de Transtornos Mentais DSM na sua quinta versão -,argumentamos que a psiquiatria se reinventa como especialidade e mobiliza o discurso da prevenção. Porém, agora é a prevenção medicalizada da infância; o hospital perde espaço para a indústria farmacêutica.

Palavras-chave: Estado. Indústria farmacêutica. Mercado. Medicalização. Psiquiatria

\section{Introdução}

Nas últimas décadas, intensificam-se as críticas ao modo de aproximação entre indústria farmacêutica e psiquiatria na produção do que os

I Doutora em Sociologia Política pela Universidade Federal de Santa Catarina (UFSC, Florianópolis, SC, Brasil) é professora associada do Departamento de Sociologia e Ciência Política na mesma Universidade, do Programa de Pós Graduação em Sociologia e Ciência Política e coordena o Núcleo de Sociologia Econômica (Nusec). A primeira versão deste artigo foi apresentada no $2^{\circ}$. Simposio CAPES COFECUB em 2019. Agradeço a CAPES o apoio através do projeto do convênio internacional CAPES COFECUB: A disseminação dos saberes espertos no domínio da Infância, no qual se integra a presente pesquisa. Contato: marciadasilvamazon@yahoo.com.br atribua a autoria da obra, forneça um link para a licença, e indicar se foram feitas alterações. 
especialistas chamam de epidemia dos diagnósticos de transtornos da infância. Entre os críticos estão Whitaker (2016), autor que denuncia a intensificação de diagnósticos tão bem comoo crescente aumento da venda de neurolépticos ${ }^{2}$ destinados à infância. Isto, em particular, a partir da publicação do Manual Diagnóstico e Estatístico de Transtornos Mentais (DSM)na sua quinta versão ${ }^{3}$. Este modelo de diagnóstico se intensifica nos EUA e se difunde para outros países em poucos anos (WHITAKER, 2016). Igualmente Sandra Caponi (2014) critica a tendência da psiquiatria em tratar como transtornos as reaçóes e emoçóes humanas naturais. Francesdenuncia igualmente o excesso de diagnósticos psiquiátricos equivocados. Esta autora aponta abusos da indústria farmacêutica e o prejuízo a milhóes de indivíduos sadios diagnosticados (os falso-positivos) submetidos a tratamentos desnecessários em reposta a emoçóes e comportamentos que são parte da experiência humana ${ }^{4}$.

Neste artigo,dedicamo-nos ao fenômeno de aproximação entre a indústria farmacêutica e a classe médica psiquiátrica na emergência dos transtornos da infância a partir da perspectiva da Sociologia dos Mercados. Interessa-nos responder a questão: qual o contexto de aproximação mais recente entre a indústria e a psiquiatria no Brasil? Argumentamos que as mudanças promovidas pelas reformas liberalizantes na década de 1990 e o momento de reforma manicomial no que toca à ação da psiquiatria pode nos fornecer pistas. $\mathrm{O}$ intuito deste artigo é abrir uma agenda de pesquisa para o estudo do tema.

A indústria farmacêutica ganhounovos contornos no Brasil a partir da aprovação da Lei de Patentesem 1996 e da criação da Política Nacional de

2 Neurolépticos (que se iniciam com a clorpromazina) são drogas com a capacidade de disciplinar e acalmar os pacientes (CAPONI, 2019, p. 133-134).

3 O DSM aumentou o número de diagnósticos, desde sua primeira versão em 1952, de pouco mais de 100 diagnósticos do DSM I para mais de 300 na última versão, o DSM 5 (BRZOZOWSKI, 2016). Para Caponi (2019), essa nova versão do DSM se constitui como um dispositivo de segurança, no sentido de Foucault, centrado na lógica da prevenção e da antecipação dos riscos.

4 O principal diagnóstico é o Transtorno de Déficit de Atenção (TDAH), considerado o transtorno mais frequente na infância. O seu diagnóstico no DSM se baseia no comportamento de desatenção, hiperatividade e impulsividade. As pesquisas na área procuram descrever as bases biológicas do TDAH para usá-las com fins diagnósticos, mas não só: igualmente como marcadores de risco, fenômeno que inaugura a prevenção medicalizada da infância (MARTINHAGO; CAPONI, 2019). Martinhago e Caponi (2019) denunciam as simplificações e omissões das pesquisas as quais pretendem vincular o TDAH aos marcadores genéticos. 
Medicamentos em 1998 (HASENKLEVER et al., 2010; KORNIS; BRAGA; PAULA, 2014). Essa mudança foi precedida pela transformação da propriedade empresarial que ocorreu na década de 1990, em particular o intenso movimento de fusóes e aquisiçóes de empresas e que se repetiu em outros setores no cenário nacional (OLIVEIRA; LABRA; BERMUDEZ, 2006).O setor farmacêutico chama atenção, não só pelo crescimento e pela concentração como também pelo fato de ampliar sua atuação para saúde animal, higiene, cuidado e nutrição dietética (KORNIS; BRAGA; PAULA, 2014).

$\mathrm{O}$ que nos interessa destacar neste artigo são as singularidades da indústria farmacêutica no Brasilno que diz respeito aos novos arranjos institucionais.

Autores como Bourdieu (2000,2006), Zelizer (1978, 1989, 1999, [1985]1994),Fligstein (2001a, 2001b) e Fligstein e Mara-Drita (1996) propóem os mercados como arbitrários culturais que, para existirem, precisam de investimentos de significados. Exemplos do mercado de casas próprias em Bourdieu (2000), o dos seguros de vida em Zelizer (1978).

Fligstein (2001) e Bourdieu $(2000,2006)$ fazem uma crítica ao liberalismo econômico que pressupóe atores racionais com preferências dadas. Segundo Fligstein(2001a, 2001b), os atores do mercado habitam mundos obscuros onde nunca se sabe quais açóes terão quais consequências. No entanto, estes atores devem encontrar uma forma de interpretar esta obscuridade, motivando os rumos da ação e justificando-a. Para Fligstein (2001a, 2001b), a ação no mercado é mais bem apreendida como tentativa de atenuar o efeito da concorrência. Ao mesmo tempo, quando falamos dos mercados voltados à saúde, é importante situar o que Foucault nomeia como medicalização: o fato de que a existência humana, conduta, comportamento e corpo se incorporaram a partir de século XVIII a uma rede de medicalizaçáo cada vez mais densa e que se apropria do campo de significação e das possibilidades semânticas (FOUCAULT, 1977). Neste artigo, interessa-nos situar o momento da crise no Brasil durante a década de 1980 e que foi acompanhada das reformas liberalizantes da década de 1990 (GRÜN, 2003; MAZON, 2009, MAZON e MOURA, 2017) e os fenômenos de mercado que dizem respeito ao setor da saúde. 
Neste contexto das privatizações,é possível observarcomo novas ações da indústria farmacêutica encontram terreno fértil em um período da reforma do modelo de atuação da psiquiatria em busca de novos espaços de atuação, fenômeno que diz respeito ao Brasil.

Os momentos de construção de instituiçóes acontecem quando uma crise social, econômica ou política ameaça arranjos institucionais antes estabelecidos (BOURDIEU, 2000; FLIGSTEIN, 2001a, 2001b). Este é o caso do Brasil no período da estagflação da década de 1980 e novo ambiente da década de 1990 (GRUN, 2003). Nessas condiçóes, atores coletivos estratégicos podem agir como empreendedores institucionais e tentar forjar novos arranjos. Os atores poderosos mais organizados podem ser convencidos de que novos arranjos são do seu interesse, mesmo que esses interesses sejam definidos e redefinidos no processo de negociação. Isso exige uma estrutura cultural que convence os atores sobre os contornos gerais dos novos arranjos (FLIGSTEIN, 2001a, 2001b).Fligstein (2001a, 2001b) defende que a formação do mercado faz parte da formação do Estado; neste ambiente, leis e práticas aceitas refletem as forças mais organizadas. Retomando Weber, Fligstein (2001a, 2001b) afirma que é o Estado o ator que cria condiçốes para que o mercado possa se tornar estável, aquele que cria e garante as regras do jogo para que as empresas possam agir: elabora leis de incentivo, dá subsídios, investe em pesquisa, em formação profissional e pode ser o principal comprador em alguns mercados, como é o caso de vacinas e outros medicamentos no setor farmacêutico.

A partir da década de 1980 houve forte defesa de instituiçôes privadas como solução para os problemas do aparato público (REARDON; BERDEGUÈ2002; GRÜN, 2003). Nesta década iniciou o movimento de acordos multilaterais com a Rodada Uruguai do Acordo Geral de Tarifas e Comércio (General Agreement on Tariffs and Trade - GATT ) precursor da OMC e que debateu os direitos de propriedade intelectual. O ajuste de diversos países ao ambiente pós Rodada Uruguai foi marcado pela substituição de importaçóes por estratégias de crescimento orientadas para exportação. Todos os países em desenvolvimento experimentam um padráo de desregulamentação interna e banalização da entrada dos IDE - Investimentos Diretos Estrangeiros (WILKINSON, 2004).Estes movimentos aconteceram em diferentes setores da economia incluindo a 
indústria farmacêutica(KORNIS; BRAGA; PAULA, 2014; HASENKLEVER et al., 2010).

Em menos de uma década, houve uma forte concentração em diferentes mercados 5 . Este movimento iniciou na Europa e Estados Unidos e se expandiu posteriormente, chegando à América Latina e ao Brasil ${ }^{6}$. No setor farmacêutico, destaque para empresas como:Johnson \& Johnson (Janssen), Pfizer, Novartis, Merk.

Exploramos, neste artigo,os contornos deste fenômeno ${ }^{7}$ no Brasil com o respectivo reforçoda psiquiatriaem um momento de reconfiguraçáo da profissão no movimento de reforma antimanicomial.O artigo está dividido em duas sessôes: a primeira identifica aspectos da sociogênese da indústria farmacêutica considerando a açáo do Estado na constituição das políticas de saúde e ambiente em que empresas atuam no Brasil. A segunda sessão explora aspectos da constituição da profissão médica, da psiquiatria e ação do Estado nesse processo ,bem como a emergência da medicalização da infância a partir da retomada das teses biologizantes como novo momento da psiquiatria.

\section{Mercados e“moléculas": medicamentos e a indústria farmacêutica em questão}

No Brasil, depois dos canais alimentares (supermercados, bares e restaurantes) as farmácias são o segundo lugar mais visitado por consumidores. É importante considerar que é alto o volume de gastos em medicamentos no consumo das famílias, principalmente as mais pobres (FIUZA; LISBOA, 2001). Já os gastos públicos com saúde no Brasil equivaleram a 3,8\% do PIB em 2015. Em 2017, a indústria farmacêutica ocupava a

5 O Brasil foi responsável por mais de 50\% de todas as fusões e aquisições internacionais registradas na América Latina em 2000 (GRÜN, 2003).

6 Principais movimentos de fusão e aquisição no setor farmacêuticoda década de 1990 até os anos 2000 no Brasil e no mundo, ver:Kornis, Braga e Paula, 2014.

7 Este artigo faz parte de um projeto mais amplo que aborda o processo de constituição do saber médico e a infância no quadro do projeto CAPES-COFECUB "Saberes espertos da infância". Em outro momento, abordaremos a indústria farmacêutica e as relações de reforço entre o saber médico e a produção/legitimação de novos medicamentos.

8 Neste quesito o país estava na posição $64^{a}$ em gastos com saúde (ranking de 183 países da OCDE), superior à média da América Latina e do Caribe e abaixo dos países desenvolvidosque aplicam em média 6,5\% do PIB em saúde; os dados são do Banco Mundial (AGÊNCIA BRASIL, 2016). 
$2^{\text {a }}$ posição no ranking de investimentos privados em $\mathrm{P} \& \mathrm{D}^{9}$. O consumo de produtos farmacêuticos difere de outras formas de mercado em que o consumidor decide diretamente pela compra. O setor farmacêutico se constitui pela compra por procuração ou medicamento ético: é necessária a prescrição e o receituário médico para que o consumo se realize ${ }^{10}$. Igualmente o medicamento diz respeito a um bem credencial: diferente do bem de busca (a qualidade é verificável antes, por exemplo: roupas, celulares) ou de um bem de experiência (a qualidade do bem é conhecida depois), os bens credenciais a sua qualidade pode nunca vir a ser passível de avaliação pelo consumidor;somente o profissional especializado pode atestar esses aspectos, certificando os bens como é o caso dos medicamentos (FIUZA; LISBOA, 2001).

Quando falamos de indústria farmacêutica e de medicina, é importante lembrarmos que estas duas áreas não se diferenciaram a não ser a partir da Revolução Industrial que marca a era das especialidades: anteriormente, fazer medicamentos, diagnosticar e prescrever receitas médicas eram tarefas de curandeiros e boticários os quais disputavam espaço e legitimidade com os médicos (FREIDSON, 2009; CALAÇA, 2005; RESENDE, 2007;).

A era industrial abriu espaço para o monopólio profissional da medicina; e, quando falamos do terreno da saúde mental, a psiquiatria no século XIX ganha o direito de definir as fronteiras sempre cambiantes entre o que é saúde e o que é doença mental"' (FOUCAULT, 1977).

A indústria farmacêutica no Brasil começou a se desenvolver no período entre 1890 e 1950 (KORNIS; BRAGA; PAULA, 2014). O impulso para este setor guarda relação com a constituição da saúde pública, o surgimento das primeiras epidemias, práticas sanitárias e o desenvolvimento

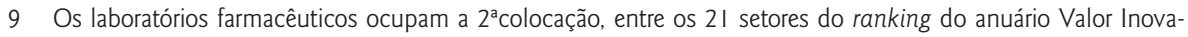
ção Brasil 2018, com o maior nível de investimento da receita líquida em atividades de Pesquisa e Desenvolvimento (PED), conforme Sociedade Brasileira Pró-inovação Tecnológica (PROTEC, 2018).

10 Nas farmácias existem ainda os medicamentos não éticos ou populares, que podem ser comprados diretamente no balcão. São os OTC (over the counter) (Hasenkleveret al., 2010, p. 52).

I I Foucault reformula a compreensão contemporânea da doença mental a partir da explicitação de sua constituição histórica. O autor retira o foco do estudo da sociedade em si mesma para a problematização das condições de produção de um discurso psiquiátrico e análise das relações entre discurso e saber (CAPONI, 2009a, 2009b). 
de medicamentos que as contivesse ${ }^{12}$ (ESCOREL; TEIXEIRA, 2008).É importante considerar como a ação de médicos desencadeia procedimentos de saúde que participarão dos processos de racionalização do Estado, que, ao conter epidemias, fundou diferentes modelos de institucionalização de atenção à saúde. Os nomes destes profissionais se confundem com as instituiçôes e práticas inauguradas por eles: o bacteriologista Oswaldo Cruz e a Fundação Oswaldo Cruz, Carlos Chagas igualmente pesquisador da Fiocruz, , Franco da Rocha na saúde mental. O processo de institucionalização foi acompanhado pela construção de códigos, leis, institutos de pesquisa e publicaçóes do setor (ESCOREL; TEIXEIRA, 2008). Então, a institucionalização da saúde é marcada pelo controle de epidemias e por um processo civilizador das formas de convívio entre seres humanos e destes com as cidades dentro de um contexto de contenção e moderação ${ }^{13}$ (ESCOREL; TEIXEIRA, 2008). O Estado brasileiro foi peça fundamental no desenvolvimento da indústria farmacêutica ao incentivar e fornecer recursos para os primeiros laboratórios farmacêuticos e foi responsável pelos próprios planos de saúde pública, produção de soros, vacinas e medicamentos.

Havia, no início do século XX, um incipiente parque industrial farmacêutico que começou a produzir anilinas, óleos, ceras e medicamentos naturais que tiveram redução após a descoberta e o emprego industrial da síntese orgânica na Europa (OLIVEIRA; LABRA; BERMUDEZ, 2006).

A partir de 1920, com açóes centradas em surtos epidêmicos de caráter emergencial as açóes do Estado passam a ser profiláticas atingindo o setor de saneamento. Este é momento chamado de era do saneamento. Na Era Vargas - período de 1930 a 1945 - foi criado o Instituto de Aposentadoria e Pensôes (IAPS), o qual dispunha de serviços médicos somado a benefícios: aposentadoria, pensóes e assistência médica eram uma única e mesma

12 A história da constituição das políticas de saúde no Brasil desde o período colonial passando pelo Império e República guarda intensa relação com os processos de migração e urbanização acompanhados por epidemias (Escorel e Teixeira, 2008). Sobre os diferentes momentos e controle das epidemias ver:Giovanella et al., 2008; Chalaça, 2005.

13 Exemplo de I89I - a primeira lei paulista da era republicana voltada para a obrigatoriedade da vacina antivariólica, já prevista no código de posturas municipais desde 1886. A obrigatoriedade e a repressão aos que se opusessem era prevista no código (ESCOREL; TEIXEIRA, 2008). 
entidade (ESCOREL; TEIXEIRA, 2008).Até o início da Primeira Guerra Mundial $^{14}$, a indústria alemã e suíça dominavam o mercado farmacêutico mundial (ORSENIGO; PAMMOLLI; RICCABONI, 2001). A Segunda Guerra Mundial, a partir da experiência da Primeira, fez com que os Estados Nacionais mobilizassem altos investimentos na indústria farmacêutica com o intuito de preservar a vida de seus soldados. Naquele ambiente, o setor farmacêutico encontrou oportunidade para ampliação e consolidação de suas condiçóes como um dos maiores complexos industriais (FIUZA; LISBOA, 2001).

O período de 1945 a 1963 caracterizou-se pelo "sanitarismo campanhista” e seguridade social. Neste período de pós-guerra e guerra fria, o Brasil se alinhou aos EUA e a ação estatal em saúde foi marcada pelo sanitarismo centralista e autoritário (ESCOREL, 2008). Oliveira, Labra e Bermudez (2006) destacam o pioneirismo do Brasil na formulação de uma política de medicamentos ao estabelecer, em 1964, a Relação Básica de Produtos Biológicos e Matérias para uso farmacêutico Humano e Veterinário.

Na década de 1970, o desenvolvimento da biotecnologia foi considerado uma mudança no paradigma tecnológico: a busca de novos medicamentos se deslocou da estratégia de primeiro desenvolver uma substância (através da síntese química) e depois aplicá-la ao corpo, para uma estratégia de síntese de proteínas as quais modificam o metabolismo humano ${ }^{15}$ (HASENKLEVER et al., 2010, p. 54).

Em 1975, com a Lei no 6.229 organizou-se o Sistema Nacional de Saúde,o qual estabeleceu competências específicas nas distintas esferas do governo, ainda com forte característica centralizadora no nível federal. $\mathrm{Na}$ década de 1980, em particular, a partir de 1985 e dentro do processo de redemocratização, nasceu o movimento nomeado como Reforma Sanitá-

14 No contexto da Primeira Guerra Mundial os soldados eram ceifados dos campos de batalha muito mais pelas doenças do que pela guerra em si. Neste ambiente que Alexander Fleming criou a penicilina, marco na história dos antibióticos.

15 Com o uso da biotecnologia, mapeia-se o organismo para identificar possíveis genes com alguma função no corpo e descobrir as proteínas a serem sintetizadas e as suas funções no organismo. A partir desse reconhecimento,foi possível atacar diretamente as doenças causadas por deficiências nessas proteínas e não apenas suas consequências como no paradigma anterior (HASENKLEVER et al., 20I0, p. 54). 
ria. O marco deste movimento foi a $8^{a}$ Conferência Nacional de Saúde de 1986 com a participação de diversos setores organizados. Esta conferência propôs uma reforma ampla do sistema de saúde;o produto desta conferência serviu de referência para a elaboração da Constituição de 1988. As garantias previstas na carta constitucional: saúde como direito e dever do Estado, universalidade da cobertura, descentralização da gestão administrativa e a integração da rede pública de serviços em um sistema único: o Sistema Único de Saúde (SUS).

Em 1996 a Lei de Patentes ${ }^{16}$ (já mencionada)que permitiu que a indústria farmacêutica fizesse pesquisas de novas moléculas e registrasse a respectiva patente no Brasil foi um marco fundamental, tão bem como a criação da Política Nacional de Medicamentos de 1998 (KORNIS; BRAGA; PAULA, 2014). Em 1999 foi criada a Agência de Vigilância Sanitária (ANVISA) assim como o Conselho de Administração de Defesa Econômica foi transformado em autarquia federal; marcos do processo regulatório sanitário e econômico respectivamente do setor farmacêutico (KORNIS; BRAGA; PAULA, 2014). O monopólio temporário do produto tem, para a firma inovadora, a importância de assegurar o mercado que mais tarde - quando expira a patente - significa um custo; quando a versão genérica concorrente pode acessar o mercado e sem o custo da pesquisa. No estágio do monopólio, a empresa inovadora irá auferir rendimento que remunere os investimentos iniciais de $\mathrm{P} \& \mathrm{D}$ daquele produto. Há, assim, uma urgência constante de pesquisa de novas moléculas para substituir aquelas que perderão a patente nos próximos anos. A proteção de produto é mais efetiva no setor farmacêutico do que, por exemplo, no setor eletrônico, porque ela tem como objeto a própria molécula ou composto químico, em vez da função que ela desempenha; nos eletrônicos, por exemplo, a função pode ser copiada por componentes de tecnologia diferente (FIUZA; LISBOA, 2001).

Nesse sentido, a linguagem desse mercado se expressa em termos dos ativos que são patenteados chamados de moléculas químicas ou simplesmente

16 "As patentes são um meio de assegurar retorno mesmo em face de elevados custos de pesquisa e riscos envolvidos para que produtores continuem investindo em novos medicamentos. A patente confere exclusividade ao detentor sobre os princípios ativos do medicamento propiciando monopólio temporário" (HASENKLEVER et al., 2010, p. 63). 
“moléculas". Se no período da década de 1980 a 1990 o ritmo de desenvolvimento de novas drogas implicou variaçóes na liderança deste mercado, hoje as grandes líderes estão estabilizadas e processos de fusão e aquisição as tornam ainda mais poderosas (FIUZA; LISBOA, 2001).

Os produtos farmacêuticos são - com destaque - os grandes beneficiários da patente. Conforme dados do Instituto de Pesquisa Econômica Aplicada (IPEA), 65\% das invenções não teriam sido lançadas e $60 \%$ não teriam sido desenvolvidos sem patentes (FIUZA; LISBOA, 2001). Daí o ambiente dos países-sede de empresas inovadoras (destaque para EUA, Japão e Comunidade Europeia) em pressionar no âmbito da Rodada Uruguai do GATT para que os demais países igualmente reconhecessem a lei de patentes.

No início do século XXI o Banco Nacional de Desenvolvimento Econômico e Social (BNDES) elaborou o Programa de Apoio ao Desenvolvimento do Complexo Agroindustrial da Saúde (PROFARMA) disponibilizando crédito para a indústria farmacêutica brasileira. É importante destacar a especificidade do Brasil e sua carta constitucional que prevê direito e acesso universal à saúde que se constitui como um país em que o Estado configura-se como apoiador de iniciativas, como já apontado, e igualmente como o maior comprador do segmento privado.

Apresentamos, nesta sessão, o papel do Estado ao incentivar por meio de leis e subsídios a constituição da indústria farmacêutica; na próxima sessão, abordamos aspectos da constituição da profissão médica pela ação do Estado para explorar o momento de aproximação entre médicos e a indústria farmacêutica.

\section{Aspectos da sociogênese da medicina e o Estado}

Como veremos nesta sessão, a profissão médica, que era uma entre outras maneiras de curar, se diferenciou de curandeiros e conquistou o monopólio do exercício da medicina garantida pelo Estado; além disso, o Estado tornou ilegais práticas que poderiam concorrer com a medicina (FREIDSON, 2009).

Conforme Freidson (2009) e Resende (2007), até a Idade Média curandeiros tratavam apenas da elite. Freidson(2009) observa que, ainda 
neste período, "praticantes populares" da medicina passaram a ser reconhecidos em documentos oficiais e o título de médico concedido pela universidade se constituía pela primeira vez em uma fonte estável de distinção. A universidade da época medieval criou, pela primeira vez, um critério administrativo, definido e distinto, estabelecendo uma identidade ocupacional singular para a medicina em meio à coleção de curandeiros (FREIDSON, 2009).

Igualmente, no Brasil a prática médica era desconhecida dos mais pobres e escravos os quais se tratavam com curandeiros; médicos disputavam espaço com outros agentes de cura. Do século XVI ao XX, intelectuais, médicos, boticários, sacerdotes, sangradores, pajés, curandeiros e parteiras disputavam o espaço de atuação na saúde. No Brasil oitocentista um dos primeiros registros de um médico é aquele especializado nas doenças femininas de nome Chomet, médico francês, formado na escola de medicina de Paris e do Rio de Janeiro. Houve resistência por parte de pais e maridos ao tratamento de mulheres no período do Império. A medicalização somente penetrou na intimidade feminina depois que o médico aderiu ao segmento para familiar tornando-se médico e compadre, cheio de afilhados (NOVAES; ALENCASTRO, [1997] 2018, p.75). Freire observa que o absolutismo do pai de família dissolvia-se à medida que outras figuras ganhavam destaque na sociedade: juiz, correspondente comercial, diretor do colégio, médico (idem).

Com a Independência do Brasil surgiram as primeiras faculdades e foi criada na corte a Sociedade de Medicina do Rio de Janeiro e, em 1831, a Academia Imperial de Medicina. No primeiro período, as açóes governamentais de saúde estavam restritas aos principais aglomerados urbanos e a algumas doenças epidêmicas. Na segunda metade do século XIX,houve um esforço de afirmação de um ponto de vista científico o qual acompanhou o desenvolvimento da sociedade capitalista. No desenvolvimento das especialidades médicas no Brasil, a psiquiatria permaneceu como campo permeável a dúvidas e contradições (CALAÇA, 2005).

Voltando a Freidson (2009), o desenvolvimento das universidades facilitou o esforço do Estado para regulamentar formalmente as ocupaçóes relacionadas à saúde. As guildas igualmente contribuíram. Nesse sentido, 
guildas e universidades ofereciam ao médico identidade pública e prestígio em relação a outras ocupações como donos de mercearia e boticários (FREIDSON, 2005).Mais tarde, no século XIX, o estabelecimento das associaçôes profissionais de Medicina na Alemanha e Inglaterra como em outros países permitiu novo impulso ao monopólio do trabalho profissional; muito embora a fidelidade do público ainda fosse frágil; recorria-se frequentemente a curandeiros (FREIDSON, 200).

Já nos EUA, no século XIX, a licença foi reconhecida e baseada em um modelo uniforme de educação médica. Ao mesmo tempo, a consolidação política da nação tornou possível o reforço das leis de licenciamento com a educação das massas, o público desenvolveu conhecimento e uma crença próxima dos médicos, tornando-se mais receptivo. O resultado foi o controle sobre a prática de cura; controle este que a medicina nunca houvera experimentado até então (FREIDSON, 2005, p.41).

Se o conceito de profissão exige o monopólio sobre o exercício profissional, segundo Freidson, acrescentamos aqui, a partir da perspectiva de Bourdieu, como o processo de formação profissional constitui um habitus cultivado: uma forma de ver o mundo e de reconhecer determinadas categorias como adequadas e não outras. Segundo Bourdieu (2001, p. 205), a cultura escolar"propicia aos indivíduos um corpo comum de categorias de pensamento que tornam possível a comunicação". Para ele,os indivíduos programados - aqueles que são dotados de um esquema homogêneo de percepção, de pensamento e de ação - constituem o "produto acabado de um sistema de ensino" (BOURDIEU, 2001, p. 206). Formar-se em uma escola significa "partilhar um espírito" literário ou científico. A cultura transmitida pela escola,

[...] a cultura erudita em sua qualidade de código comum é o que permite a todos os detentores associar os mesmos sentidos às mesmas palavras, aos mesmos comportamentos e às mesmas obras [...] a Escola incumbida de transmitir esta cultura, constitui o fato de consenso cultural nos termos de uma participação no senso comum entendida como condição da comunicação. O que os indivíduos devem à Escola é, sobretudo, um repertório de lugares comuns, não apenas um discurso e uma linguagem comuns, mas também terrenos de encontro e acordo, problemas comuns e maneiras comuns de abordar os problemas comuns. (BOURDIEU, 200I, p.206-207). 
Freidson define a medicina como uma profissão de consulta ${ }^{17}$, depende da decisão do paciente leigo, ele é livre para escolher. "A escolha pela consulta não pode ser forçada,antes, precisa ser atraída" (FREIDSON, 2005, p. 41). Quando falamos de mercado profissional, portanto, este se constitui como um espaço de lutas por reconhecimento e as lutas pelos critérios de classificação da realidade ${ }^{18}$. Distanciamo-nos, portanto, de uma visão funcionalista da constituição profissional para uma perspectiva relacional, conforme Bourdieu (2006, 2001).

A autonomia profissional não é absoluta, o Estado tem soberania sobre todos e concede autorização de profissão a alguns (FREIDSON, 2005). Freidsonobserva a importância das associaçôes profissionais. No exemplo estadunidense, a Associação Médica Americana (AMA) se subdivide em braços estaduais e territoriais; os médicos são admitidos no braço municipal, o que confere poder local. Raramente existe oposição, os mesmos membros se reelegem (FREIDSON, 2005, p.48). Esta é, para este autor, a forma típica das associaçôes ocupacionais: observa-se apatia política dos jornais que não publicam opiniôes opostas e oferecem ao mundo externo uma aparência unitária, mesmo que haja luta interna ${ }^{19} . \mathrm{O}$ maior poder é o da inexistência de outras associaçóes; a filiação é critério de competência profissional (FREIDSON, 2005, p. 49). As associaçóes fixam normas mínimas de formação e credenciamento e mantêm o associado atualizado em técnicas. A AMA tem influência sobre carreiras individuais e papel de destaque sobre normas técnicas mínimas para o funcionamento dos serviços de saúde. Ela esteve engajada por décadas, na promoção de qualidade de produtos farmacêuticos, alimentos dietéticos e dispositivos terapêuticos e diagnósticos.

De forma semelhante, no Brasil, o Conselho Federal de Medicina (CFM),com sede no Distrito Federal, tem jurisdição em todo território nacional e atua em conjunto com os Conselhos Regionais de Medicina.

17 Freidson diferencia profissão de consulta de profissão erudita, acadêmica. Segundo este autor o que se espera do médico é o "faça algo por mim" que é diferente da profissão erudita do: "diga se isto é verdadeiro ou falso" (FREIDSON, 2005, p. 4I).

18 Este será o tema de artigo futuro: as disputas por reconhecimento entre médicos e sua relação com a indústria farmacêutica.

I9 Idem, análise de uma pesquisa futura. 
OsConselhosRegionais formam uma autarquia dotada de personalidade jurídica de direito público, com autonomia administrativa e financeira. Os Conselhos foram instituídos pelo Decreto-Lei no 7.955, de 1945, e adquiriram suas características atuais a partir da Lei no 3.268, de 1957(CFM, 2019).

Para cumprir suas funçóes legais, os Conselhos Regionais funcionam como tribunais, apreciando denúncias contra médicos e instaurando processos ético-profissionais quando existem indícios de infração ética. As apenaçôes, na forma da lei, podem consistir em advertência confidencial, censura confidencial, censura pública, suspensão do exercício profissional até 30 dias e cassação do exercício profissional. O órgão possui um corpo de Conselheiros, os quais são eleitos por seus pares para mandato meramente honorífico, sem remuneraçáo. Os Conselhos Regionais, como no modelo estadunidense, dividem com o Ministério da Educação a regulamentação do profissional médico, conforme art. 17 da Lei no 3.268, de 1957:

Art. 17. Os médicos só poderão exercer legalmente a medicina, em qualquer de seus ramos ou especialidades, após o prévio registro de seus títulos, diplomas, certificados ou cartas no Ministério da Educação e de sua inscrição no Conselho Regional de Medicina, sob cuja jurisdição se achar o local de sua atividade. (CFM, 2019, [s. p.]).

Quando abordamos as doenças mentais é no período entre os séculos XVII e XIX no Brasil que a assistência aos doentes mentais se tornou médica. Surgiu e se difundiu, a partir da França, o modelo erigido por Pinel e instituído por Esquirol, e a assistência aos doentes se transformou em responsabilidade médica e estatal.

Apresentamos, a seguir, aspectos da psiquiatria com o intuito de discutir sua aproximação recente com a indústria farmacêutica na produção dos diagnósticos da infância.

\section{I Sociogênese da psiquiatria e a reforma psiquiátrica}

Foucault observa medicina e psiquiatria pelo que as separa e o que as une: a instituição hospital e o asilo, as práticas e a forma de estabelecer o diagnóstico. Foucault (1977) concentra sua análise na comparação entre estudos médicos, anatômicos e neurológicos de um lado e os estudos psi- 
quiátricos de outro. $\mathrm{O}$ intuito é distinguir o corpo anatomopatológico da medicina e a ausência de corpo da psiquiatria. Este autor chama a atenção para a especificidade da psiquiatria em relação à medicina: a ausência da evidência das lesóes ${ }^{20}$; e, para a psiquiatria, o binarismo do diagnóstico ao definir se um paciente está ou não louco, se deve ou não ser internado (FOUCAULT, 1977; CAPONI, 2009a, 2009b).

Conforme observa Caponi (2009a, 2009b) o movimento de desmanicomialização e a reforma psiquiátrica irão descentralizar velhas tecnologias de poder antes investidas na internação. Como veremos nesta sessão o momento da desmanicomialização guarda coincidência com a inauguração das novas classificaçôes de doenças mentais que atingem a abordagem preventiva da infância.

$\mathrm{Na}$ área da saúde mental o marco institucional da assistência psiquiátrica brasileira acontece com o decreto imperial que criou o Hospício Pedro II para tratamento de alienados. Estefoi inaugurado em 1852, e sua função era exclusivamente segregadora (RESENDE, 2007). Desde então e por 150 anos, a política nacional de saúde mental se resume a mera implantação de hospitais psiquiátricos (AMARANTE, 2008, p. 636). O período posterior à Proclamação da República constitui o marco entre a psiquiatria empírica e o início da chamada psiquiatria científica: ocorre a laicização dos asilos, a ascensão dos representantes da classe médica na direção das instituiçóes e como porta-vozes do Estado (RESENDE, 2007, p. 43). Em 1903, no governo Rodrigues Alves, Juliano Moreira assumiu a Assistência a Alienados e a gestão do Hospício Nacional enquanto Oswaldo Cruz assumiu a direção dos serviços de saúde pública: serão considerados os dois "gigantes" de seu tempo - o primeiro na medicina sanitária e o segundo na medicina mental (RESENDE, 2007, p. 45). Este momento é identificado

20 "Na medicina do século XIX iniciaram os processos de correlação entre sintomas e lesões como forma de evidência das doenças; é possível individualizar diversas doenças e classificar sintomas estabelecendo vínculos entre lesões e a caracterização de doenças. É a atribuição orgânica da lesão o que possibilita, para a medicina, a construção de diagnósticos diferenciais. Um signo e um sintoma remetem a uma lesão específica, o que permite diagnosticar uma doença e não outra. No âmbito da psiquiatria a situação muda por dois fatores. O primeiro, embora existam diagnósticos como melancolia, esquizofrenia ou transtorno bipolar, não importa tanto a precisão nosológica quanto saber se este paciente é ou não louco. Antes de qualquer caracterização, a questão maior que se coloca é uma oposição binária, está em questão um decisão institucional sobre a internação" (CAPONI, 2009a, p. 98). 
como de grande atividade científica: a classificação brasileira das doenças mentais apoiada por duas sociedades - Sociedade de Psiquiatria, Neurologia e Ciências afins e a Liga de Higiene Mental ${ }^{2 !}$ (RESENDE, 2007). $\mathrm{O}$ aparecimento das colônias permitiu que o modelo asilar dominasse a assistência psiquiátrica até 1950 .

A Liga Brasileira de Hygiene Mental22foi fundada por Gustavo Reidel, diretor da colônia de psicopatas do Engenho de Dentro. O objetivo de Reidel era promover a nova psiquiatria ampliando assim o escopo da profissão psiquiátrica na vida cotidiana e promovendo um programa de higiene mental, em especial para os pobres e criminalmente insanos (COSTA,1976). A liga se preocupou com a delinquência juvenil, prostituição, alcoolismo entre outras (STEPAN, 2012, p. 343). Em 1941, Adauto Botelho (discípulo de Juliano Moreira ${ }^{23}$ ) assumiu o recém-criado Serviço Nacional de Doenças Mentais (SNDM) dentro do Ministério da Educação e Saúde. Naquele momento predominaram os hospitais públicos, respondendo por $80,7 \%$ dos leitos psiquiátricos do país. Os asilos (Juqueri, em São Paulo; Hospital Nacional dos Alienados, no Rio de Janeiro; e São Pedro, em Porto Alegre) exerciam um papel orientador da assistência psiquiátrica, consolidando a política macro-hospitalar pública como principal instrumento de intervenção sobre a doença mental (PAULIN; TURATO, 2004, p. 242).

Este foi o momento em que a psiquiatria procurou se estabelecer como especialidade médica e seu espaço de atuação, o hospital,foi reconhecido igualmente. O Código Brasileiro de Saúde de 1945 condenava denominaçôes como "hospício", "asilo", "retiro" ou "recolhimento", reconhecendo a categoria hospital. Novas técnicas terapêuticas foram introduzidas no país em substituição ao papel meramente custodial predominante. Métodos

21 Como observa este foi um período em que o campo científico não estava completamente estabelecido no Brasil: não havia departamento de ciências nas universidades e o trabalho biológico restringia-se às escolas de medicina, institutos agrícolas e o Instituto Oswaldo Cruz, este que talvez fosse o mais conhecido centro de pesquisa médica da América Latina (STEPAN, 1978;,).

22 "Cabe lembrar que o movimento higienista no Brasil ganhou peso entre as décadas de 1900 e 1940 . Por ser um país de população católica, rural, racialmente mista e analfabeta, o Brasil representava tudo o que os europeus consideravam disgênico" (STEPAN, 2012, p. 334-335). "O Brasil era considerado como exemplo ideal da degeneração que ocorria em nações tropicais racialmente híbridas” (STEPAN, 2012, p. 338).

23 Juliano Moreira foi o nome mais importante da psiquiatria brasileira no primeiro quarto de século, defendeu um caráter científico à psiquiatria no Brasil (PAULIN; TURATO, 2004). 
da psiquiatria biológica foram inaugurados: choque cardiazólico, psicocirurgia, insulinoterapia e a eletroconvulsoterapia (PAULIN; TURATO, 2004). Ao mesmo tempo em que a classe médica psiquiátrica lutava por seu reconhecimento como especialidade médica, o hospital psiquiátrico se impunha como espaço de atuação (PAULIN; TURATO, 2004). Outro fator marcante desta década em diante foi o aumento no número de leitos psiquiátricos no país: o processo de privatização da assistência médica e da previdência social (AMARANTE, 2008).

Esse modelo foi radicalizado no período da ditadura militar com o golpe de 1964; a privatização faz crescer o número de leitos no país. Naquele momento, 97\% do volume de recursos disponíveis em psiquiatria eram destinados à internação hospitalar (AMARANTE, 2008;PAULIN; TURATO, 2004). O processo da reforma psiquiátrica iniciou ao final da década de 1970 e no bojo da redemocratização. Em 1978, no cenário de redemocratização, havia denúncia de maus tratos nos hospitais não só a pacientes como também aos presos da ditadura. Houve demissóes e protestos e,naquele momento, nasceu o Movimento dos Trabalhadores da Saúde Mental (MTSM). Houveuma crítica epistemológica ao saber psiquiátrico e uma crítica à psiquiatria como estratégia de repressão.

A 1 a Conferência Nacional da Saúde Mental realizada em 1987 compôs a agenda do movimento de reforma psiquiátrica questionando o modelo de hospitalização e defendendo a criação de serviços extra-hospitalares. Em 1993, organizou-se o Movimento Nacional de Luta Antimanicomial, já queBrasil acompanhava o movimento da reforma psiquiátrica de outros países como Inglaterra, França, EUA e Itália (AMARANTE, 2008).

Ao mesmo tempo em que havia o desmonte do sistema manicomial, criaram-se os Núcleos de Atenção Psicossocial (Naps) abertos 24 horas. O Projeto de Lei de 1989 (3.657/89) propôs a extinção progressiva dos manicômios. Na década de 1990, a experiência dos hospitais-dia e centros de convivência se difundiu. O Programa Nacional de Avaliação de Serviços Hospitalares de 2002 foi um dispositivo de redução dos leitos hospitalares. Conforme Amarante (2008), é necessário destacar o papel dos Ministérios Públicos Estaduais que, a partir da ocorrência de óbitos e violência em hospitais psiquiátricos, impetraram medidas de reversão do modelo. Havia 
resistência da psiquiatria privada que alarmava a sociedade que poderia estar sendo desassistida.

Um ciclo histórico da saúde pública no Brasil foi concluído com a aprovação da Lei no 10.216, em 2001, promotora da reestruturação da assistência psiquiátrica no país. Esta lei é fruto de um movimento que avançou desde o final da década de 1970 e década de 1980,nomeado de “reforma psiquiátrica” (PAULIN; TURATO, 2004, p. 241).Em 2011, o Brasil contava com 596 residências - lares abrigados para os desmanicomializados. Igualmente a Estratégia da Saúde da Família (ESF) tem atuação articulada com a saúde mental no contexto da Reforma Psiquiátrica o que pressupóe ruptura com o modelo biomédico centrado no hospital (AMARANTE, 2008).O poder, antes concentrado na figura do médico, se distribui por equipes multiprofissionais e se desloca da ação isolada nos manicômios para espaços abertos e compartilhados com outros profissionais.

\subsection{A indústria de diagnósticos e a medicalização da infância}

Como citado anteriormente, o início do século XX foi o momento da descentralização da atuação psiquiátrica. Ele guardou coincidência com o movimento das classificaçóes de doenças mentais relacionadas à infância. Há uma multiplicação de novos diagnósticos e cada vez mais a aceitação da ideia de que pequenos sinais anunciadores de uma patologia mental futura possam ser diagnosticados desde a infância o que pressupóe intervenção medicamentosa preventiva desde esse período; fenômeno nomeado como medicalização da infância. O Brasil é o segundo maior consumidor de psicotrópicos na infância, em particular metilfenidato (Ritalina), atrás apenas dos EUA (CAPONI, 2016).

$\mathrm{O}$ discurso da psiquiatria apresentou o uso de medicamentos para crianças e adolescentes como momento do avanço médico. Conforme Whitaker (2016), esta prática iniciou nos EUA; posteriormente, difundiu-se por outros países e continentes. Este autor considera o fenômeno historicamente datado e situa como elemento fundante a publicação da terceira edição do DSM em 1980. As classificaçóes em psiquiatria e que estão documentadas nas diferentes versóes do DSM foram criadas com a finalidade de obter dados estatísticos sobre a população e buscar uma linguagem 
universal sobre as patologias mentais (MARTINHAGO; CAPONI,2019). Foi o momento em que a Associação Americana de Psiquiatria adotou o modelo médico para caracterizar transtornos psiquiátricos: "os transtornos passaram a ser considerados desde então como doenças do cérebro com diagnósticos feitos na presença de sintomas" (WHITAKER, 2016, p. 13).

A retomada das teses biologizantes e cerebrais na psiquiatria ao final do século XXabriu espaço para a indústria farmacêutica ampliar a venda de psicotrópicos. Conforme Brzozowski (2016), Martinhago e Caponi (2019) - autoras que retomam Foucault (1977) -, até a década de 1950 não era comum na prática psiquiátrica a delimitação de categorias de doenças ${ }^{24}$. O primeiro manual da Associaçáo Americana de Psiquiatria (APA) foi o DSM I que refletia uma visão psicodinâmica da personalidade próxima aos estudos da psicanálise. O DSM II mantém esta referência abordando sintomas como reflexos das condiçóes gerais dinâmicas subjacentes ou como reaçóes a momentos de crise. O DSM III de 1980 surgiu em meio aos conflitos pelos quais passava a psiquiatria questionada pelo seu subjetivismo e pela sua falta de cientificidade. O DSM III inaugurou a visáo dos transtornos mentais a partir de uma lista de sintomas em ruptura com as versôes anteriores. $\mathrm{O}$ intento era levar para a psiquiatria o modelo diagnóstico das demais áreas da medicina - nelas o diagnóstico é o centro da prática, como já mencionado.

Conforme pondera Whitaker (2016), a partir da década de 1980 iniciou um movimento de aproximação entre a indústria farmacêutica e a Associação Psiquiátrica Americana (APA), associação responsável pela edição do DSM. Este foi o momento em que a APA adotou o que é chamado de modelo médico para categorizar transtornos psiquiátricos, vistos a partir de então como doenças do cérebro; diagnósticos a partir da presença de sintomas. "Este raciocínio promove a ideia de que os medicamentos psiquiátricos devem ser a primeira linha de tratamento para estes transtornos" (WHITAKER, 2016, p. 13-14). Conforme o autor, este fenômeno aproximou a APA das indústrias farmacêuticas as quais passaram

24 A última classificação que antecede o primeiro Manual Diagnóstico e Estatístico de Transtornos Mentais (DSM) surgiu em 1918, com 22 categorias. Desde 1952 até 2013, o Manual foi reformulado até a quinta edição (BRZOZOWSKI, 2016). 
a patrocinar eventos científicos da área, fornecerem ajuda financeira para encontros médicos e mesmo patrocinaram diretamente profissionais psiquiatras na Europa, Ásia e América do Sul para comparecerem aos encontros da APA e, assim, assimilarem o novo paradigma de cuidado. Em outra linha de atuação, a indústria farmacêutica investiu na contratação de psiquiatras de faculdades de medicina para serem seus líderes de opinião. Esses líderes criaram a narrativa que levou à expansão de prescrição de medicamentos psiquiátricos para todos os segmentos da sociedade americana incluindo as crianças. "Estes profissionais trabalharam conduzindo ensaios clínicos, publicando artigos, livros didáticos e discursando sobre a validade dos transtornos psiquiátricos em cursos de Educação Médica Continuada”(WHITAKER, 2016, p. 15). Observa-se aqui como a divisão entre produtores de bens e produtores de ideias se esvanece, aproximando-se o campo da indústria farmacêutica dos intelectuais produtores de bens simbólicos: os médicos atuarão produzindo os bens (pesquisas científicas e artigos) como produzindo um ponto de vista sobre eles (palestras e cursos).

Por último, trazemos como exemplo desta aproximação e dos novos contornos da relação entre médicos e a indústria farmacêutica no Brasil o manual de boas práticas elaborado e assinado pelas principais entidades brasileiras representantes da classe médica: Conselho Federal de Medicina (CFM), Associação Médica Brasileira (AMB) e Sociedade Brasileira de Cardiologia (SBC) na condição de representantes da classe médica brasileira e a Associação da indústria Farmacêutica de Pesquisa (INTERFARMA) - entidade que representa parte da indústria farmacêutica no Brasil(CFM, 2017). Nomeado como "Em defesa das boas práticas no relacionamento entre a classe médica e a indústria farmacêutica”, está disponível no Portal do CFM e no site da Interfarma. O documento prevê limites legais no relacionamento entre as empresas do setor farmacêutico e os médicos. No caso do pagamento de despesas de transporte, hospedagem, alimentação, estas devem ser compatíveis com as circunstâncias dos serviços contratados. O documento proíbe a entrega de materiais de interesse científico a estudantes de medicina a náo ser durante eventos médicos; o apoio a profissionais para participar de eventos(nacionais ou internacionais) não pode estar condicionado à prescrição e/ou à dispensação de um determinado medicamento. Igualmente é proibida a realização de congresso em local de 
apelo turístico ou, ainda, a compra de passagem de avião na primeira classe (CFM, 2017; INTERFARMA, 2016). Observa-se aqui o que Bourdieu (1989, p. 548) nomeia como alongamento do circuito de legitimaçáo: as classes dominantes são obrigadas a invocar "[...] o universal para exercer sua dominação e elas não podem se ausentar de ser tomados em seu próprio jogo de submeter sua pratica às normas pretendentes à universalidade". Aqui as entidades anunciam a norma e se declaram fieis a ela; logo, a indústria farmacêutica legitima a classe médica e vice-versa.

\section{Considerações finais}

Este artigo abordou a relação entre indústria farmacêutica e psiquiatria no contexto das reformas liberalizantes a partir da ótica da Sociologia Econômica que compreende os mercados como construçóes sociais. Na primeira sessão, abordamos a constituição da indústria farmacêutica à luz da construção do sistema de saúde no Brasil. A institucionalização da saúde é marcada pelo controle de epidemias e por um processo civilizador das formas de convívio entre os seres humanos e destes com as cidades, elementos fundantesdo ambiente propício para o florescimento da indústria farmacêutica. Fligstein (2001a,) defende que a formação do mercado faz parte da formação do Estado; neste ambiente, leis e práticas aceitas refletem as forças mais organizadas.Foi possível observar a atuação do Estado brasileiro na constituição do ambiente estável para que as empresas farmacêuticas se consolidassem conforme diferentes momentos em diferentes modelos de atenção à saúde ora centralizadores e, a partir da constituição do Sistema Único de Saúde, um modelo descentralizado e universal. Conforme Bourdieu (2006) e Fligstein (2001a, 2001b),momentos de crise, como foi a estagflação da década de 1980 no Brasil, podem trazer mudanças na forma de atuação do Estado e condiçóes fluidas podem fazer emergir novas formas de mercado como foi o movimento de fusóes e aquisiçóes que estabilizou o mercado farmacêutico (entre outros) na forma de multinacionais.

Com a Lei de Patentes, as empresas inovadoras passaram a utilizar o recurso da patente como forma de restringir o acesso à produção e comercialização de seus produtos, podendo, assim, monopolizar temporariamente seu mercado. Ou, mobilizando a linguagem da sociologia, estas 
estratégias permitiram estabilizar o mercado e evitar a guerra aberta. A aproximação entre indústria farmacêutica e a classe médica é constante;da classe médica,vêm alguns dos pesquisadores produtores das vacinas no momento das grandes epidemias no Brasil. Os médicos participavam dos movimentos de reformas da saúde e,quando o assunto foi a psiquiatria, urgiareformular sua atuação a partir do momento da reforma antimanicomial.

A atuação psiquiátrica no Brasil, ao longo do século XX, saiu de um modelo centrado no hospital para outro descentralizado. Naquele momento de descentralização que se iniciou uma aproximação entre indústria farmacêutica e a psiquiatria. No século XXI e a partir da publicação do DSM na sua quinta versão, inaugurou-se a estratégia de medicalização e retomada da biologização agora dos transtornos da infância em uma atuação denominada de caráter preventivo. Os psiquiatras foram os produtores do objeto e de um ponto de vista sobre o objeto: os transtornos da infância.

Este artigo deixa como pista de pesquisa um aprofundamento sobre o processo de internacionalizaçáo da profissão psiquiátrica, tanto no seu espaço de atuação como espaço de formação. Estudar as articulaçóes sociais que produzem esta internacionalização e suas formas de naturalização são temas bem-vindos.

\section{Referências}

AGÊNCIA BRASIL. Brasil gasta 3,8\% do PIB em saúde pública. 2016. Disponível em: http:// agenciabrasil.ebc.com.br/economia/noticia/2018-11/brasil-gasta-38-do-pib-em-saude-publica. Acesso em: 2jul. 2019.

AMARANTE, P. D. C. Saúde mental, desinstitucionalização e novas estratégias de cuidado. In:GIOVANELLA, L.; ESCOREL, S.; LOBATO, L. V. C.; NORONHA, J. C.; CARVALHO, A. I. (org.). Política e Sistema de Saúde no Brasil. Rio de Janeiro: Fiocruz, 2008. p. 735-760.

BOURDIEU, P. La noblesse D’Etat. Grands ecoles et esprit de corps. Les Editions de Minuit, 1989. BOURDIEU, P. O poder simbólico. 3. ed. Rio de Janeiro: Bertrand Brasil, 2000.

BOURDIEU, P. A economia das trocas simbólicas. 5. ed. São Paulo: Editora Perspectiva, 2001. BOURDIEU, P. As estruturas sociais da economia. Porto: Campo das Letras S.A, 2006.

BRZOZOWSKI, F. S. Discurso biológico cerebral e a expansão de diagnósticos psiquiátricos. In:CAPONI, S.; VÁSQUEZ VALENCIA, M. F.; VERDI, M. (org.).Vigiar e medicar: estratégias de medicalização da infância. São Paulo: LiberArs, 2016. p. 147-160. 
CALAÇA, C. E Capítulos da história social da medicina no Brasil. Ciência e Saúde Manguinhos, v. 12, n. 2, p. 557-566, 2005.

CAPONI, S. História do poder psiquiátrico.Ciência e Saúde Coletiva, v. 14, n. 1, p. 95-103, 2009a.

CAPONI, S. Biopolítica e medicalização dos anormais. Physis: Revista de saúde coletiva,Rio de Janeiro, v. 19, n. 2, p. 529-549, 2009 b.

CAPONI, S. O DSM como dispositivo de segurança. Physis: Revista de saúde coletiva, Rio de Janeiro, v. 24, n. 3, p. 741-763, 2014.

CAPONI, S. Vigiar e medicar: o DSM 5 e os transtornos ubuescos da infância. In: CAPONI, S.; VÁSQUEZ VALENCIA, M. F.; VERDI, M. (org.).Vigiar e medicar: estratégias de medicalização da infância. São Paulo: LiberArs, 2016. p. 29-46.

CAPONI, S. Uma sala tranquila. Neurolépticos para uma biopolítica da indiferença. São Paulo: LiberArs, 2019.

CONSELHO FEDERAL DE MEDICINA (CFM).Atualizaçáo de posicionamento conjunto: em defesa de boas práticas no relacionamento entre a classe médica e a indústria farmacêutica, 2017.Disponível em: http://portal.cfm.org.br/images/PDF/documento_interfarma.pdf. Acesso em: 16 jul. 2019.

CONSELHO FEDERAL DE MEDICINA (CFM).Institucional.2019. Disponível em: http:// portal.cfm.org.br/.Acesso em: 16 jul. 2019.

COSTA, J. F. História da Psiquiatria no Brasil, Rio de Janeiro: Ed. Documentário, 1976

ESCOREL, S. História das políticas de saúde no Brasil de 1964 a 1990: do golpe militar a reforma sanitária.In:GIOVANELLA, L.; ESCOREL, S.; LOBATO, L. V. C.; NORONHA, J. C.; CARVALHO, A. I. (org.). Política e Sistema de Saúde no Brasil. Rio de JaneiroFiocruz, 2008. p. 385-434.

ESCOREL,S.;TEIXEIRA,L.A.HistóriadaspolíticasdesaúdenoBrasilde1822a1963:do impérioaodesenvolvimentismopopulista.In:GIOVANELLA, L.; ESCOREL, S.; LOBATO, L. V. C.; NORONHA, J. C.; CARVALHO, A. I. (org.). Política e Sistema de Saúde no Brasil. Rio de Janeiro Fiocruz, 2008.p.333-384.

FIUZA, E. P. S.; LISBOA, M. B. Bens credenciais e poder de mercado: um estudo econométrico da indústria farmacêutica Brasileira. Technical report. Texto para discussão n. 846. Rio de Janeiro: IPEA, 2001.

FLIGSTEIN, N.; MARA-DRITA, I. How to make a market: reflections on the attempt to create a Single Market in the European Union.Am. Journal of Sociology, v. 102, n. 1, p. 1-33, 1996.

FLIGSTEIN, N.Mercado como política: uma abordagem político-cultural das instituiçóes de mercado.Contemporaneidade e Educaçáo, ano 6, n. 9, p.26 -55, 2001 a.

FLIGSTEIN, N. Le mythe du marché, Actes de la Recherche, v. 139, n. 1, p. 3-12, 2001 b. 
FOUCAULT, M. História de la medicalización. Educación médica y salúd, v. 11, n. 1, p. 1-23, 1977.

FREIDSON, E.Profissáo médica: um estudo da sociologia do conhecimento aplicado.São Paulo: Edit. UNESP; Porto Alegre: Sindicato dos Médicos, 2009.

GIOVANELLA, L.; ESCOREL, S.; LOBATO, L. V. C.; NORONHA, J. C.; CARVALHO, A. I. (org.). Política e Sistema de Saúde no Brasil. Rio de Janeiro: Fiocruz, 2008.

GRÜN, R. Atores e ações na construção da governança corporativa brasileira. RBCS, v. 18, n. 52, p. 149-218, 2003.

HASENKLEVER, L.; FIALHO, B.; KLEIN, H.; ZAIRE, C. Economia industrial de empresas farmacêuticas.Rio de janeiro: E-papers; FAPERJ, 2010.

INTERFARMA.Código de conduta. 2016. Disponível em: https:/www.interfarma.org.br/ public/files/biblioteca/codigo-de-conduta---revisao-2016-interfarma2.pdf.Acesso em: 3 jul. 2019.

KORNIS, G. E. M.; BRAGA, M. H.; PAULA P. A. B. Transformaçóes recentes da indústria farmacêutica: um exame da experiência mundial e brasileira no século XXI. PhysisRevista de Saúde coletiva, v. 24, n. 3, 2014. Disponível em: http://www.scielo.br/pdf/physis/v24n3/01037331-physis-24-03-00885.pdf. Acesso em: 8 jul. 2019.

MARTINHAGO,F.;CAPONI, S.Breve história das classificaçóes em psiquiatria. R. Inter. Interdisc. INTERthesis, v. 16, n. 1, p. 74-91, 2019.

MAZON, Marcia S. Padrôes de qualidade e segurança alimentar no terreno institucional brasileiro. Dados, v. 52, n. 4, p. 1003-1044, 2009.

MAZON, Marcia S; MOURA, W. G. Cachorros e humanos. Mercado de raçóes pet em perspectiva sociolólogica. Civitas. Revista de Ciencias Sociais. V. 17 n. 1, p. 138-158, 2017.

NOVAES; ALENCASTRO, [1997] 2018. NOVAIS, F(coord) ALENCASTRO, L. F. (org) História da vida privada no Brasil II - Império: a corte e a modernidade nacional, 9a. Reimpressão, 1997(2008). SP: Companhia das Letras,

OLIVEIRA, E. A.; LABRA, M. E.; BERMUDEZ, J. A produção pública de medicamentos no Brasil: uma visão geral. Cad. Saúde Pública, Rio de Janeiro, v. 22, n. 11, p. 2379-2389, nov. 2006.

ORSENIGO, L.; PAMMOLlI, F. O.; RICCABONI, M. Technological change and network dynamics:lessons from the pharmaceutical industry. Research Policy, Milan, v. 30, n. 3, p. 485508, 2001.

PAULIN, L. F.; TURATO, E. R. Antecedentes da reforma psiquiátrica no Brasil. Historia, ciência e saúde Manguinhos, v. 11, n. 2, 2004.Disponível em: http://www.scielo.br/pdf/hcsm/v11n2/01. pdf. Acesso em: 5 jul. 2019.

PORTAL CFMLei no 3.268 de1957. 2019. Disponível em: http://portal.cfm.org.br/index. php?option=com_content\&id=21736:lei. Acesso em: 5 jul. 2019. 
REARDON, T.; BERDEGUE, J. The Rapid Rise of Supermarkets in Latin America: Challenges and Opportunities for Development”. Development PolicyReview, v. 20, n. 4, p. 371-388, 2002. RESENDE, 1946?.

RESENDE, H. Política de saúde mental no Brasil. Uma visão histórica. In:TUNDIS, S. A.; COSTA, N. R.Cidadania e loucura:políticas de saúde mental no Brasil. 8. ed. Rio de Janeiro: Vozes: 2007. p. 15-73.

SOCIEDADE BRASILEIRA PRÓ-INOVAÇÃO TECNOLÓGICA (PROTEC). Indústria farmacêutica é o setor que mais investe em inovaçáo no Brasil. 9 jul. 2018. Disponível em: http://protec.org.br/farmacos-e-medicamentos/36695/industria-farmaceutica-e-o-2-setor-quemais-investe-em-inovacao-no-brasil.Acesso em: 12 jul. 2019.

STEPAN, L. Beginnings of brazilian science. Oswaldo Cruz, Medical Research and Policy 1890-1920. Revue d'histoire de sciences, v. 31, n. 1, 1978. Disponível em: https://www.persee.fr/docAsPDF/ rhs_0151-4105_1978_num_31_1_1555.pdf. Acesso em: 5 jul. 2019.

STEPAN, L. Eugenia no Brasil: 1917-1940. In:HOCHMAN, G. E.; ARMUS, D. (org.). Cuidar, controlar e curar. Ensaios históricos sobre saúde e doença na América Latina e Caribe. RH: Fiocruz, Coleçấo Hostória e Saúde, 2012. p. 331-391.

WHITAKER, R. Transformando crianças em pacientes psiquiátricos: fazendo mais mal do que bem. In: CAPONI, S.; VÁSQUEZ VALENCIA, M. F.; VERDI, M. (org.).Vigiar e medicar: estratégias de medicalização da infância. São Paulo: LiberArs, 2016. p. 13-29.

WILKINSON. J., “The Food Processing Industry, Globalization and Developing Countries”. Journal of Agricultural and Development Economics, vol. 1, no 2, p. 184-201.

ZELIZER, V. Human values and the market: the case of life insurance and death in 19th-century America. American Journal of Sociology, v. 84, p. 591-610, 1978.

ZELIZER, V. The social meaning of money: "special moneys". American Journal of Sociology, v. 95 , n. 2, p. 342-377, sep. 1989.

ZELIZER, V. [1985]. Princing de priceless child. The changing social value of children. Princeton University Press: [S.l.], 1994.

ZELIZER, V. Multiple markets, multiple cultures. In: SMELSER, N.; ALEXANDER, J. (ed.).Diversity and its discontents. Princeton University Press: [S. l.], 1999. p. 193- 212. 


\section{Pharmaceutical industry and psychiatry within the framework of Economic Sociology. A research agenda}

\section{Abstract}

In this article we were interested in analyzing the relationship between the pharmaceutical industry and psychiatry and new contours of this relationship from the 1990s in Brazil. We argue, from the perspective of Economic Sociology which understands markets as social constructions, that this process gains a particular design in the country. The purpose of the article is to open a research agenda in the health and pharmaceutical industry from this framework. The methodology used was literature review and document analysis. When we talk about Brazilian psychiatry, in the 1940s this sector struggled for professional recognition with the discourse of disease prevention and the psychiatric hospital sought its space. At the heart of recent transformations of psychiatry reform and medicalization processes - in particular from the publication of the DSM Diagnostic and Statistical Manual of Mental Disorders in its fifth version - we argue that psychiatry reinvents itself as a specialty and mobilizes the discourse of prevention. However, it is now the medicalized prevention of childhood; the hospital loses space for the pharmaceutical industry.

Keywords: State. Pharmaceutical industry. Medicalization. Market. Ppsychiatry. 